\title{
Posthumanism: The human body transition
}

\section{Can reconstruction of the human body reveal a new transition phase for the human species into an as yet unknown living form?}

\author{
Anna Nazo \\ Artist; Fine Art Research, Contemporary \\ Art Practice (Performance) \\ Russia / United Kingdom \\ annanazo@gmail.com
}

\begin{abstract}
This practice-led research focuses on posthumanism: the human body transition. The work is placed at the intersection of digital-physical performance, embodiment and body engineering, and contemporary technology. The study investigates a currently topical discourse on posthumanist scenarios, bioengineering, postgenderism, astrobiology, cosmology.
\end{abstract}

Posthumanism. Futurology. Digital-physical performance. Technology. Body transition. Embodiment. Cyborgization. Gender fluidity. Androgyny. Outer space exploration.

\section{EXTENDED ABSTRACT}

What does it mean to think beyond humanism? Is it possible to craft a mode of philosophy, ethics, and interpretation that rejects the classic humanist divisions of self and other, mind and body, society and nature, human and animal, organic and technological? Can a new kind of humanities/ posthumanities respond to the redefinition of humanity's place in the world by both the technological and the biological or 'green' continuum in which the 'human' is but one life form among many (Wolfe, 2010)?

This practice-led research focuses on posthumanism: the human body transition, particularly, by means of bionic reconstruction, bio technologies, robotics. The work is placed at the intersection of digital-physical performance, embodiment and body engineering, and contemporary technology. In its attempt to bridge the gap between art, science and technology, the study addresses the broad question: how do we become posthuman? The project approaches this question through an examination of possibilities of revealing a new transition phase for the human species into an as yet unknown living form. This can be achieved through reconstruction of the human body, and investigation of a currently topical discourse on posthumanist scenarios, bioengineering, gender fluidity, androgyny, xeno- and astrobiology, cosmology, and outer space exploration.

The writing begins with an examination of what it is that constitutes posthumanism in a wider perspective, uncovering some social phenomena in relation to the theme, such as technophilia, technophobia, current issues in relation to gender fluidity, androgyny, cyborgization, etc. The correlation between posthumanism and body is examined first, then the interrelation between performance, science and technology. Eventually the work looks at the ways in which a performance artist, manipulating their body, scientific data and emerging technology, can contribute to revealing a next evolutionary phase for the human species, can enhance an awareness of increasing issues related to futures, and, can possibly encourage different perspectives on posthumanism.

Philosophically, the study leans on posthumanism theories, uncovered by Donna Haraway, Cary Wolfe, N. Katherine Hayles, et al; and furthers these ideas into the art work. It aspires to explore and to elaborate the possibilities of the medium, body itself. The work investigates the body as language, and the body as sculpture in performance art, and looks at the body and its relationship with technologies, as a medium for artistic expression, referring to pioneers in the field: Stelarc, ORLAN, Oron Catts and lonat Zurr. 
The practical work consists of a series of experiments with technology, body, movements, that enmesh the future skin concept and transformations of the human body. The work also contains a set of soundscapes, and video and image documentations of the investigation. This research eventually will result in multi-sensorial installations and performances with body augmentations and/or mixed reality scenarios.

The work aims to contribute to articulating future possibilities of the relationship of technology and the body architecture. The contribution can be important to the postgender-related discussion in relation to digital technologies, data and bodies; to the augmented and mixed reality issues relating to the body, and also the themes of embodiment, bodies of matter and data bodies. The objects encapsulate different layers of information and might encourage different perspectives on posthumanism.

\section{REFERENCES (SELECTED)}

Barrett, L. (2011) Beyond the Brain: How body and environment shape animal and human minds. UK: Princeton University Press.

Dixon, S. (2007) Digital Performance. USA: The MIT Press.

Dvorsky, G., Hughes, J.(2008) Postgenderism: Beyond the Gender Binary. http://ieet.org/archive/IEET-03-PostGender.pdf (retrieved 26 March 2015).

Hayles, N. K. (1999) How We Became Posthuman: Virtual Bodies in Cybernetics, Literature and Informatics. USA: The University of Chicago Press.

Hayles, N. K. (2002) Writing Machines. UK: The MIT Press.

Walker Art Center. (1981) Chance Conversations: An Interview with Merce Cunningham and John Cage.

https://www.youtube.com/watch?v=ZNGpjXZovgk (retrieved 6 January 2016).

Warr, T. (2000) The Artist's Body. UK: Phaidon Press.

Wennemann, D. (2015) Posthumanisms: A Carnapian Experiment.
http://ieet.org/index.php/IEET/more/wennemann20 150319 (retrieved 26 March 2015).

Wolfe, C. (2010) What is Posthumanism? USA: University of Minnesota Press.

Zylinska, J. (2009) Bioethics in the Age of New Media. USA: The MIT Press.

\section{FIGURES}

In Figures 1 and 2, I worked with human body, embodiment and self-perception, using $3 d$ scanning, and widely with a question of self and identity through a posthuman lens.

In the piece in Figures 3 and 4, I work with embodiment of cognition. I work with EEG data, creating a journey into human's mind. I refer to Hayles's posthumanism scenarios on the fate of embodiment in an information age and the cultural and technological construction of the cyborg, which imagines a triumphant transcendence of embodiment and 'privileges informational pattern over material instantiation' (Hayles, 1999).

I further these ideas, translating the recording of electrical activity along the scalp into a digital surface that reacts to a change of a human's brain activity. I look at the performance of the brain, and how the perception of its observation by a performer affects their behaviour.

In the work I refer to Duchamp's concept of 'triangle', which is in the work represented by performer's body, technology and the audience. All elements are interconnected and are in a conversation, and there is never the same conversation - 'it is like in the weather you don't know when one thing begins... being together in a same place in a same time and living the space around each art' (Cage, 1981).

During the piece, the performer is allocated in a room with everyday objects, such as a table, chair, bed, etc. The performer wears an EEG headset connected to computer and monitors. The piece consists of a sequences of performer's movements, human's everyday 'rituals', using the objects in the room. The viewer sees the performer alongside with a screen, which shows life a data of performer's brain activity. 

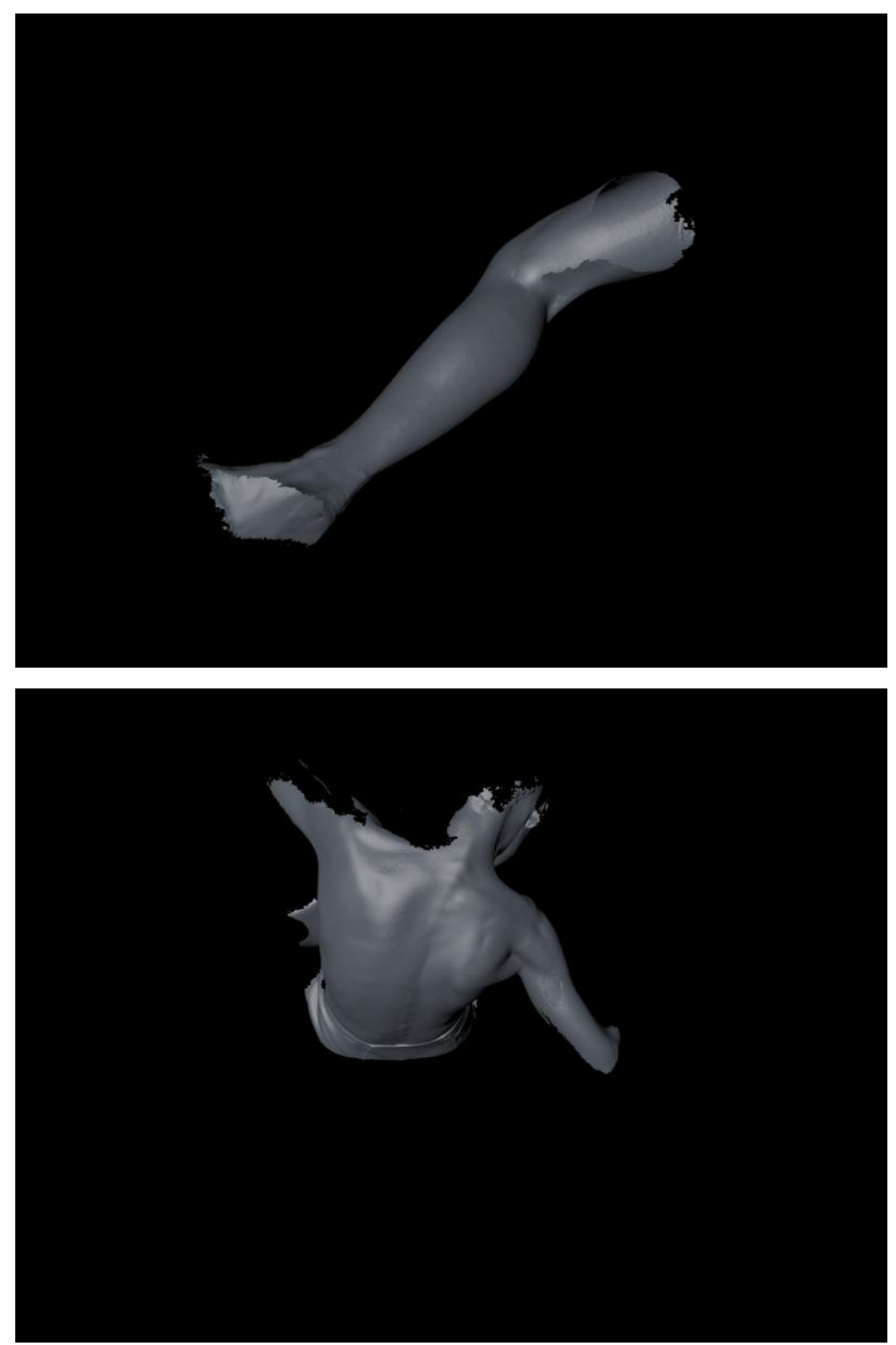

Figure 1, 2: \#Human. 3D scans of performer's body. In series I question the process of capturing the life, 'the moment,' a personal database in one quick snapshot, embodiment of our 'self', mirror of our reality. 

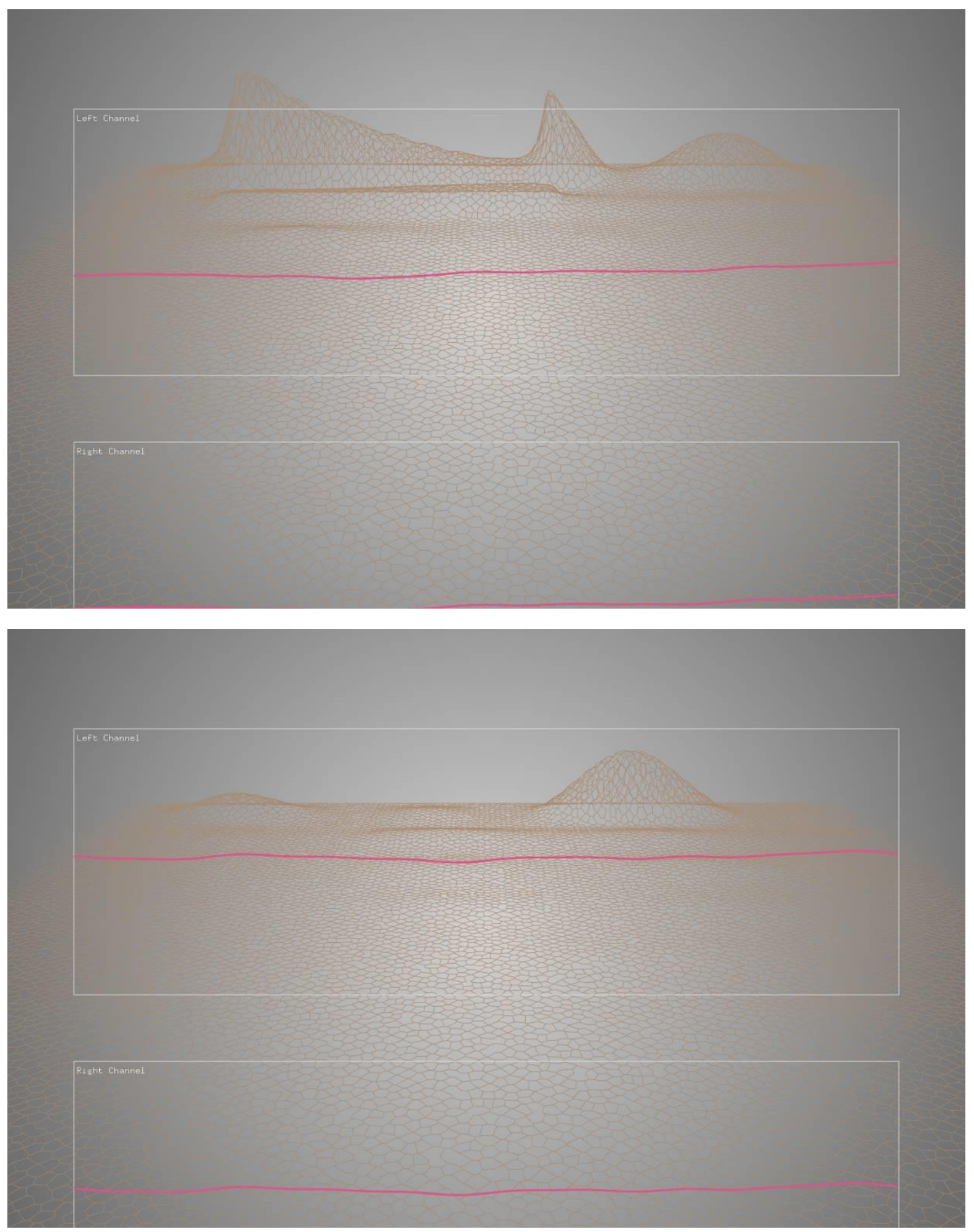

Figure 3, 4: States of mind. Embodiment of cognition. Performance, installation. Performer's brain activity translated into a digital surface. Screen shots. Data via NeuroSky EEG headset. Programming Vincent Rebers. 